\title{
Construcción de la conciencia ambiental para trabajar en y desde la escuela
}

\author{
CONSTRUCTION OF THE ENVIRONMENTAL CONSCIENCE TO WORK IN AND FROM THE \\ SCHOOL \\ CONSTRUÇÃO DA CONSCIÊNCIA AMBIENTAL PARA TRABALHAR EM E DESDE A ESCOLA
}

\author{
Diego Ramiro Castro Castro* / diracc21@yahoo.com \\ Fredy Valencia Valbuena** / frevalval@yahoo.com \\ Juan Carlos Mendoza Mendoza*** norfolkjucame@gmail.com
}

\section{Resumen}

El presente texto nace de la investigación de un grupo de docentes sobre la información curricular ambiental que los estudiantes reciben en el aula y su relación con lo expresado en los medios de comunicación, reflexionando sobre el debate entre la enseñanza tradicional y los intereses de los estudiantes. Se realizó en dos instituciones educativas de Bogotá y abarcó tres fases, dentro de las que cabe destacar la inclusión del enfoque CTS $+\mathrm{A}^{1}$, en donde se formularon categorías de análisis a partir de la metodología investigación-acción, que arroja imaginarios sobre problemáticas ambientales locales.

\section{Summary}

This investigation arises from the research of a group of teachers about environmental curriculum information that students receive in the classroom and its relationship with that expressed in the media, reflecting on the debate between traditional teaching and students' interests. It was conducted in two educational institutions in Bogota and covers three phases: one of them, the CTS+A approach, where analysis categories were developed from the action-research methodology, showing collective imaginaries about local environmental issues.

\section{Resumo}

Esta investigação nasce da indagación de um grupo de docentes sobre a informação curricular ambiental que os estudantes recebem no aula e sua relação com o expressado nos meios de comunicação, reflexionando sobre o debate entre o ensino tradicional e os interesses dos estudantes. Il s'a réalisé en deux institutions éducatives de Bogota et jembrasse trois phases: une d'elles l'approche CTS+A en où sont formulés des catégories d'analyses à partir de la metodología recherche - action, que lance des imaginaires sur des problématiques environnementales locals.

\section{Palabras clave}

Consciencia ambiental, bucles, fuentes hídricas, CTSA, género

\section{Keywords}

Environmental conscience, loops, hydric sources, CTSA, gender

\section{Palavras chave}

Consciência Ambiental, Bucles, fontes hídricas, CTSA e Género.

\footnotetext{
* Director del Centro de Investigaciones Facultad Ciencias del Educación, Universidad Libre de colombia; Candidato a Doctor en Pedagogía, Universidad de Granada, España.

** Docente en el Centro Integral "José María Córdoba" I.E.D. Magister en Docencia de la Química Universidad Pedagógica Nacional; Docente Catedrático en el Departamento de Física de la Universidad Pedagógica Nacional.

*** Docente del Colegio Gimnasio Cecil Reddie; Especialista en Gerencia y Proyección Social de la Educación de la Universidad Libre.

1 Ciencia, Tecnología, Sociedad y Ambiente.
}

Fecha de recepción: 19 de Marzo de 2012 / Fecha de aprobación: 8 de junio de 2012 


\section{Antecedentes y contexto de estudio}

Esta reflexión pedagógica gira alrededor de las prácticas cotidianas y los encuentros realizados por un grupo de profesores interesados en el tema ambiental; inicia en el año 2005 con la convocatoria abierta por la Escuela Pedagógica Experimental (EPE) para conformar la Red de Ciencias Naturales y Educación Ambiental. Se construye a partir de la búsqueda del acercamiento de las niñas y niños, a problemáticas que se presentan en su entorno inmediato y que no son tenidas en cuenta en las prácticas de la escuela, temas que sin embargo, generan discursos que resultan totalmente ajenos a los estudiantes.

Vemos que el discurso Ambiental se queda en palabras, teorías y legislación, pero la acción orientada por la toma de consciencia no es consecuencia de lo planteado. A partir de los encuentros se detectaron diversos intereses en el grupo y se inició un diálogo acerca de las percepciones del trabajo ambiental, que permitió expresar inquietudes como: ¿Qué entendemos por ambiente? ¿Cómo entendemos la Educación Ambiental? ¿Cuál es la diferencia entre ecología y educación ambiental? ¿Cuál es el ambiente del ser humano? ¿Cuál es concepto de éxito y qué determina nuestro estilo de vida? ¿Qué es sobrevivir?; preguntas que son retomadas constantemente por el grupo de investigación1.

\section{Preguntas directrices}

Basados en las nuevas concepciones epistemológicas del saber científico, y en las teorías contemporáneas de aprendizaje, ¿qué diseños de alternativas pedagógicas, para la enseñanza de las ciencias naturales, generan responsabilidad con mi especie humana, y con la vida del planeta tierra, para fomentar la consciencia ambiental al interior de las aulas escolares? Esta fue una pregunta fundamental que permitió el surgimiento de los siguientes interrogantes: 1) Desde los espacios de los medios de comunicación, de la comunidad y los contextos propios de la escuela ¿Cómo se identifican los lenguajes que circulan en los sujetos que asisten a la escuela? 2) ¿Qué papel cumple la escuela en la relación medios de comunicación y contextos sociales?

\footnotetext{
1 Grupo de investicación reconocido por Colciencias: La enseñanza y el aprendizaje. Código: Col: 0004209. Corporación EPE (Corporación Escuela Pedagógica Experimental).
}

76 nodos y nudos / volumen 4 N.은 32 / enero-junio 2012

\section{Ruta de indagación}

\section{Marco de referencia}

Según Arroyo y Mandolini (2006), el trabajo del investigador no comienza desde cero: antes de toda investigación se encuentra con una realidad que siempre está representada por un conjunto de conocimientos a los que se les suele llamar (impropiamente) "conocimiento vulgar", en cuya trama se encuentran percepciones, conocimientos sapienciales de origen comunal y político, bajo la forma de representaciones religiosas, valoraciones étnicas, cuerpos doctrinales filosóficos, etc.; también por los "sedimentos" de teorías científicas preexistentes y de los hechos científicos que "se tienen" por bien establecidos, que, de manera fragmentaria pero eficaz, ocupan el espíritu del hombre cuando se dispone a realizar un trabajo investigativo.

La globalización según Olavarría (2008), implica una perceptible pérdida de fronteras en el quehacer cotidiano de la economía, la información, la ecología, la técnica, los conflictos transculturales y la sociedad civil, que modifica la vida y la fuerza para adaptarse y responder a esta nueva realidad. Las problemáticas planteadas invitan a trabajar el proceso conceptual y práctico, centrándose en las complejas relaciones entre sujeto-organismo y entorno natural-social, que hasta hoy se sustentan en principios desarrollistas economicistas (Capra, 2003).

De la misma forma, es necesario disctutir la forma en que se viene desarrollando la EA en las instituciones, que se ha caracterizado por pocos escenarios de reflexión y construcción de conocimiento en cuanto a temas de biodiversidad, formación crítica y modelos de desarrollo, que son necesarios en el ámbito latinoamericano para enfrentar problemáticas de sociedades consumistas, de exclusión o espacios que, en términos de Gadotti, significan una disminución de los mínimos vitales:

Mientras en los mercados aumentan el volumen de los artilugios tecnológicos, escasean el río limpio para nadar o pescar, la quinta con sus árboles, el aire puro, el agua potable, las calles donde se pueda jugar o pasear, la fruta comida sin miedo a la química, el tiempo disponible, los espacios de socialización informal (Gadotti, 2002). 


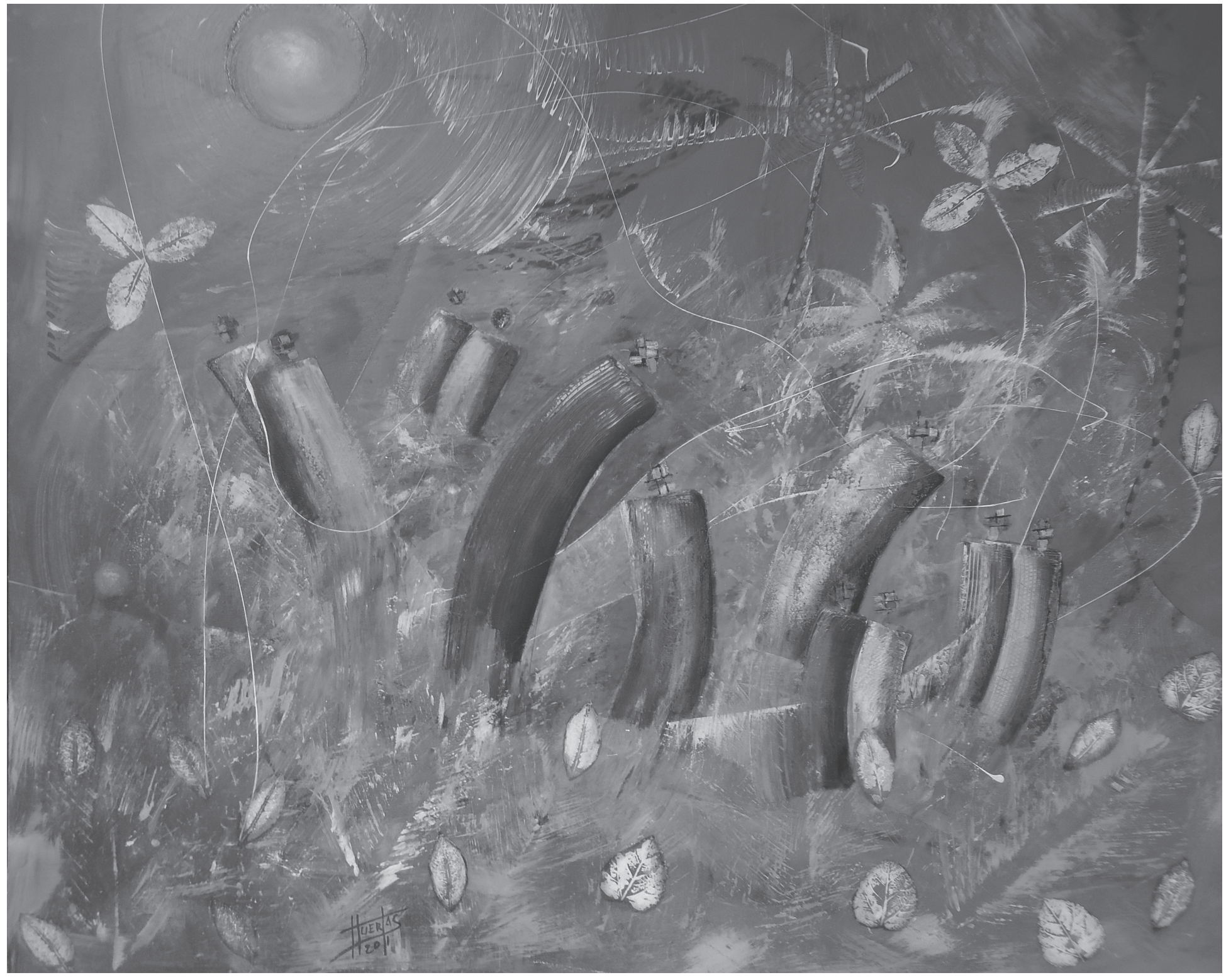

Segundo Arístides Huertas Torres ॥ Título: de la serie caminantes ॥Técnica: Óleo sobre tela ॥ Dimensiones: $140 \mathrm{~cm}$ x $140 \mathrm{~cm}$ 
El equipo le apuesta a la comprensión del planeta Tierra como asociación de vida, por eso la pertinencia de preguntarnos ¿Qué es la vida?. En estos términos, Lovelock (1993), en su teoría de Gaia expone que los trabajos de los naturalistas y biólogos aún tienen dificultades en definir científicamente lo que es la vida, por lo que podemos establecer que a no es ya el estudio de la biosfera, entendida como la parte de la Tierra en que normalmente existen los seres vivos (Odum, 2001).

Por otro lado, este contexto establece un debate entre la enseñanza tradicional y las nuevas corrientes, en cuanto que la primera expone una débil relación de los contenidos de la enseñanza, en particular de las ciencias, con los intereses de los estudiantes, en este sentido se requiere tomar distancia de las actividades que sólo conducen a la memorización de la información, para centrarse en actividades de construcción de conocimiento, en donde la información disponible sea un insumo en los procesos de elaboración de conocimiento (Segura, 1999). Es así como el presente trabajo de consciencia ambiental, pretende generar un acercamiento inicial del estudiante, y sus maestros, a las problemáticas de las fuentes hídricas, existentes a su alrededor, que son desconocidas.

Las diferencias mostradas en las respuestas de niños y niñas, nos llevan a reflexionar acerca de la construcción de la consciencia ambiental desde la perspectiva de género, que según Solbes y Vilches (1989), es posible porque la educación ambiental está diseñada para apoyar el desarrollo de actitudes, opiniones y creencias. Este tipo de estudios en enseñanza de las ciencias, se refiere a la visión del currículo de ciencias equilibrado desde la perspectiva de género (Sahuquillo, Jiménez, Domingo y Álvarez, 1993).

Es por ello que resulta pertinente el cuestionamiento que Sahuquillo, et al., realizan acerca de la enseñanza de las ciencias desde la visión de los alumnos varones, en el sentido de que ignora el papel fundamental de la mujer, hecho que se hace evidente en la inexistencia de contenidos y metodologías equilibrados: es posible que los autores de materiales curriculares hayan tenido la intención de marginar a la mujer. Al respecto se destaca, en particular la década de los 80, la línea de investigación "niñas y ciencias", que luego se conoce como "género y ciencia", que cuestiona la forma de planificar el currículo, organizar la clase y en general la forma de enseñar ciencias.
Medios de comunicación y educación informal de la sociedad

Según Quiles (2004), sin importar si se trata de una educación reglada o de una educación no reglada, es inevitable reconocer en la actualidad la relación profunda e inequívoca entre ésta y la comunicación. $\mathrm{Al}$ interesarnos por los elementos que participan en el acto educativo y el comunicativo, encontramos que son idénticos en ambos casos, llegando a identificar diez afinidades que Sarramona (1994) utiliza para elaborar un esquema que pone de manifiesto la sistematicidad de un proceso.

Para Giddens (2001), el análisis de los efectos de los medios sobre la población llevó a McLuhan a considerar seriamente, hace ya más de treinta años, que el planeta acabaría siendo una "aldea global" en muchos aspectos de la vida de las personas que lo habitan, de forma tal, que buena parte de las actividades productivas y de ocio se verían homogeneizadas por la imposición de patrones de todo tipo: económicos, culturales, sociales, etc.

Una alternativa metodológica para comprender las percepciones de los niños y niñas en cuanto a las elaboraciones conceptuales desarrolladas en el aula, que para nuestro caso se ocupa de la conciencia ambiental, es la que se desarrolla en Ciencia, Tecnología, Sociedad y Ambiente (CTSA), que pretende la formación de ciudadanos críticos frente al papel la ciencia en la actualidad. Con respecto a este particular Solbes y Vilches (1989), plantean posibilitar una enseñanza contextualizada y pertinente a los intereses de los estudiantes, a partir de las discusiones de grupo centradas en el aprendizaje cooperativo. Así mismo, Caamaño (1995), pretende enseñar las ciencias en concordancia con el planteamiento de situaciones reales que, a través del diálogo, el saber escuchar, argumentar y controvertir con argumentos sólidos, permitan actuar consecuentemente.

\section{Descripción del trabajo de campo}

El presente trabajo pretende encontrar el eje central que permita el desarrollo de ideas individuales susceptibles de convertirse en colectivas, para favorecer un contexto escolar y social en la práctica ambiental. La idea es replantear la información que los estudiantes captan en el aula, el cómo la asimilan, relacionan y analizan respecto de la información que proviene del exterior (medios de comunicación). 
El aula entonces se convierte en un espacio generador de ideas, contrario a lo que sucede en la actualidad en donde no se le da la trascendencia que merece, debido a la falta de un análisis concreto de la información; por esto, el trabajo en el aula será de tipo reflexivo y permitirá enriquecer los contenidos del currículo, generando una flexibilidad a través de un proceso de acción-reflexión que se logra con y para el sujeto. Con el desarrollo de encuestas los estudiantes replantean, indagan, discuten y comparan temas actuales, originando otra visión de los acontecimientos.

\section{Metodología}

El trabajo realizado es de carácter descriptivo, interpretativo y explicativo, combinando los métodos de análisis cualitativos y cuantitativos (mixto) (Cardona, 2002 y Hernández, Fernández y Baptista, 2006), todo, a partir de la metodología de investigación-acción (I-A), que presenta la planeación-reflexión-observación-acción, como procesos dinámicos en espiral que contribuyen de manera dinamizadora, a encaminar y reorientar los presupuestos investigativos que en lo teórico y lo práctico establezcan objetivos comunes.

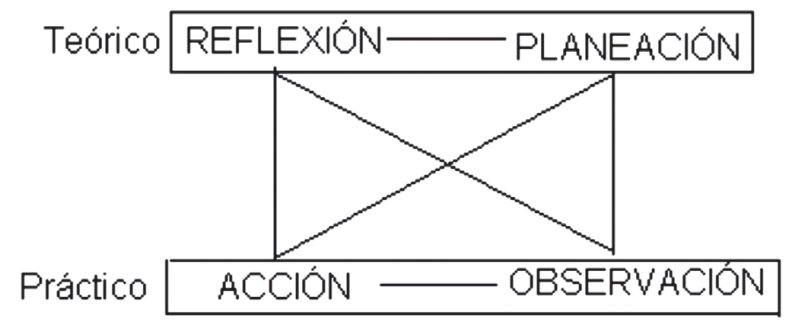

Figura 1. Cuadro de metodología en investigación-acción

En la presente investigación se manejan dos momentos relacionados con el tipo de instrumentos aplicados en las preguntas: el primero, que busca indagar sobre las ideas espontaneas de los estudiantes a partir de la formulación de una pregunta; y el segundo, que aparece cuando se realiza una encuesta de pregunta abierta sobre noticias reales, y permite recopilar información sobre un conocimiento, buscando que los estudiantes hagan una comprensión de la realidad con sus ideas previas.
Se utiliza el software cualitativo Atlas.ti como herramienta para el análisis e interpretación de la información, a través del establecimiento de categorías y subcategorias que emergen de la interacción profesorestudiante y posibilita entrecruzar la estadística descriptiva, en la medida en que se realize la aplicación de los instrumentos (encuestas, entrevistas, diarios de campo y protocolos).

\section{Población de estudio}

La población que interviene en el proceso se compone de estudiantes de los grados quinto y sexto del Centro Integral "José María Córdoba" Institución Educativa Distrital. Además de los estudiantes de los grados séptimo y octavo del Gimnasio Cecil Reddie, Institución Educativa Privada; ambas instituciones ubicadas en Bogotá, D.C. (Colombia). La población total consta aproximadamente de 150 estudiantes.

\section{Instrumentos}

Se diseñaron y aplicaron tres instrumentos tipo encuesta con pregunta abierta; el primero indaga sobre las ideas previas que tienen los estudiantes sobre ¿Qué es la vida? y ¿Cómo surge la vida?; el segundo instrumento pregunta ¿Qué es el agua?, como idea previa, y luego lo realiza manejando el mismo concepto después de la lectura de un artículo sobre una inundación. Finalmente, el tercer instrumento indaga ¿Qué es el $\mathrm{AH}_{1} \mathrm{~N}_{1}$ ?, ¿qué es un virus?, y propone la elaboración de un dibujo de un virus y la relación del agua con el virus $\mathrm{AH}_{1} \mathrm{~N}_{1}$ A partir del análisis del discurso de los niños y niñas participantes, se elaboran las categorías que se relacionan en las tablas síntesis de resultados.

\section{Resultados}

Siendo una investigación cualitativa enmarcada en la metodología de I-A, se presentan los avances teóricoprácticos, evidenciando las tendencias de género (mujeres y hombres) en relación con determinadas categorías.

\section{Instrumento $N^{o} 1$}

Se aplicó el instrumento $\mathrm{n}^{\circ} 1$ reconociendo básicamente tiene dos momentos, el primero indaga sobre ¿Qué es la vida?, y el segundo consiste en preguntar cómo surge la vida; las respuestas por genero y la identificación de cada una de las categorías pueden observarse en la Tabla 1. 


\section{Instumento $\mathbf{N}^{0} 1$}

\begin{tabular}{|c|c|c|c|c|c|c|c|c|c|}
\hline \multicolumn{10}{|c|}{ ¿Qué es la vida? } \\
\hline \multirow[b]{2}{*}{ Categorías } & \multirow{2}{*}{ Grados } & \multicolumn{2}{|c|}{5} & \multicolumn{2}{|c|}{6} & \multicolumn{2}{|c|}{7} & \multicolumn{2}{|c|}{8} \\
\hline & & M & $\mathrm{H}$ & M & $\mathrm{H}$ & M & $\mathrm{H}$ & M & $\mathrm{H}$ \\
\hline Religiosa & & 6 & 4 & 4 & 3 & 3 & 3 & 2 & 2 \\
\hline Humanística & & & & & & 5 & 2 & 4 & 10 \\
\hline Biogénesis & & 14 & 4 & 6 & 4 & 1 & 4 & & \\
\hline Estética & & 8 & 22 & 3 & 8 & 1 & 3 & 6 & 2 \\
\hline Economicista & & & & & & & & & 2 \\
\hline Sin relación con las anteriores & & 8 & 2 & & & & & & \\
\hline \multicolumn{10}{|c|}{ Algunas respuestas de los estudiantes } \\
\hline \multicolumn{10}{|c|}{$\mathrm{H}$ : la vida es lo que uno tiene para poder disfrutar el mundo } \\
\hline \multirow{3}{*}{$\begin{array}{l}\text { Respuestas en } \\
\text { primaria }\end{array}$} & & \multicolumn{8}{|c|}{ H: la vida es saberla disbrutar, jugar-celebrar y estudiar } \\
\hline & & \multicolumn{8}{|c|}{$\begin{array}{l}\text { M: yo pienso que para mí la vida significa ser algo, nacer, vivi } \\
\text { tante vivir }\end{array}$} \\
\hline & & \multicolumn{8}{|c|}{ M: es o que se muere, y ara, crece, se reproduce o se mueve } \\
\hline \multirow{4}{*}{\multicolumn{2}{|c|}{ Respuestas en secundaria }} & \multicolumn{8}{|c|}{$\begin{array}{l}\text { H: la vida es un tiempo en el que el ser vivo nace y vive y muere; en ese tiempo los seres vivos } \\
\text { interactúan con su entorno y con las demás especies }\end{array}$} \\
\hline & & \multicolumn{8}{|c|}{ H: la vida es un ciclo de procesos de un ser vivo } \\
\hline & & \multicolumn{8}{|c|}{$\begin{array}{l}\text { M: la vida es todo lo que en este momento está ocurriendo y sigue ocurriendo, y pasan cosas } \\
\text { buenas y malas y alegres y felices, hasta que uno se muere y queda el cuerpo inerte sin vida }\end{array}$} \\
\hline & & \multicolumn{8}{|c|}{ M: la vida es el conjunto del alma y cuerpo que hacen que un ser viva, piense y reaccione } \\
\hline \multicolumn{10}{|c|}{ ¿Cómo surge la vida? } \\
\hline \multirow[b]{2}{*}{ Categorías } & \multirow{2}{*}{ Grados } & \multicolumn{2}{|c|}{5} & \multicolumn{2}{|c|}{6} & \multicolumn{2}{|c|}{7} & \multicolumn{2}{|c|}{8} \\
\hline & & M & $\mathrm{H}$ & M & $\mathrm{H}$ & M & $\mathrm{H}$ & M & $\mathrm{H}$ \\
\hline Religiosa & & 26 & 20 & 8 & 6 & 1 & 1 & 6 & \\
\hline Humanística & & 4 & 2 & 3 & 3 & 1 & 4 & 2 & 4 \\
\hline Biogénesis & & 4 & 8 & 2 & 5 & 9 & 7 & 2 & 14 \\
\hline Sin relación con las anteriores & & 2 & 2 & & & & & & \\
\hline \multicolumn{10}{|c|}{ Algunas respuestas de los estudiantes } \\
\hline \multirow{4}{*}{\multicolumn{2}{|c|}{$\begin{array}{l}\text { Respuestas en } \\
\text { primaria }\end{array}$}} & $\begin{array}{l}\text { H: la vid } \\
\text { aprender }\end{array}$ & $\begin{array}{l}\text { ó por } \\
\text { obre }\end{array}$ & $\begin{array}{l}\text { os la } \\
\text { do }\end{array}$ & ra que & ndiéra & respe & y no & \\
\hline & & $\begin{array}{l}\mathrm{H}: \text { Dios } \\
\text { humanos }\end{array}$ & $\begin{array}{l}\text { munc } \\
\text { idos A }\end{array}$ & $\begin{array}{l}\text { é los } \\
\text { Eva, }\end{array}$ & $\begin{array}{l}\text { os an } \\
\text { urgie }\end{array}$ & s que & taba a & s prin & eres \\
\hline & & M: la vid & rgió c & s hu & que tc & n hijos & s hijos & & \\
\hline & & M: mi vi & ició & que $n$ & a barr & $\mathrm{mi} \mathrm{m}$ & & & \\
\hline & & $\begin{array}{l}\text { H: la vid } \\
\text { interactú }\end{array}$ & $\begin{array}{l}\text { tiem } \\
\text { su er }\end{array}$ & $\begin{array}{l}\text { l que } \\
\text { y con }\end{array}$ & $\begin{array}{l}\text { vivo } n \\
\text { nás e }\end{array}$ & $\begin{array}{l}\text { vive } y \\
\text { s }\end{array}$ & re, en & npo I & sivos \\
\hline Pocrurctos on crundari & & H: la vid & ciclo & ceso & ser $v$ & & & & \\
\hline Respuestas en secundarıa & & $\begin{array}{l}\text { M: la vid } \\
\text { buenas y }\end{array}$ & $\begin{array}{l}\text { do lo } \\
\text { y ale }\end{array}$ & $\begin{array}{l}\text { este } \\
\text { elice } \\
\end{array}$ & $\begin{array}{l}\text { to es } \\
\text { que } \\
\end{array}$ & $\begin{array}{l}\text { iriend } \\
\text { muer }\end{array}$ & $\begin{array}{l}\text { gue oc } \\
\text { deda el }\end{array}$ & $\begin{array}{l}\text { o, y } \\
\text { o iner }\end{array}$ & $\begin{array}{l}\text { osas } \\
\text { iida } \\
\end{array}$ \\
\hline & & M: la vid & conji & $\mathrm{l}$ alm & rpo q & cen qu & ser viv & se y r & \\
\hline
\end{tabular}

Tabla 1. Categorías y respuestas de los estudiantes

80 nodos y nudos / volumen 4 N. 32 / enero-junio 2012 


\section{Instrumento $\mathrm{N}^{\circ} 2$}

Posteriormente se aplicó, en dos momentos, el instrumento no 2, que indaga acerca de ¿Qué es el agua?; las respuestas de los y las estudiantes, y su organización en las categorías, (utilitaria, temáticas, estética y biogénesis), se evidencian en la Tabla 2.

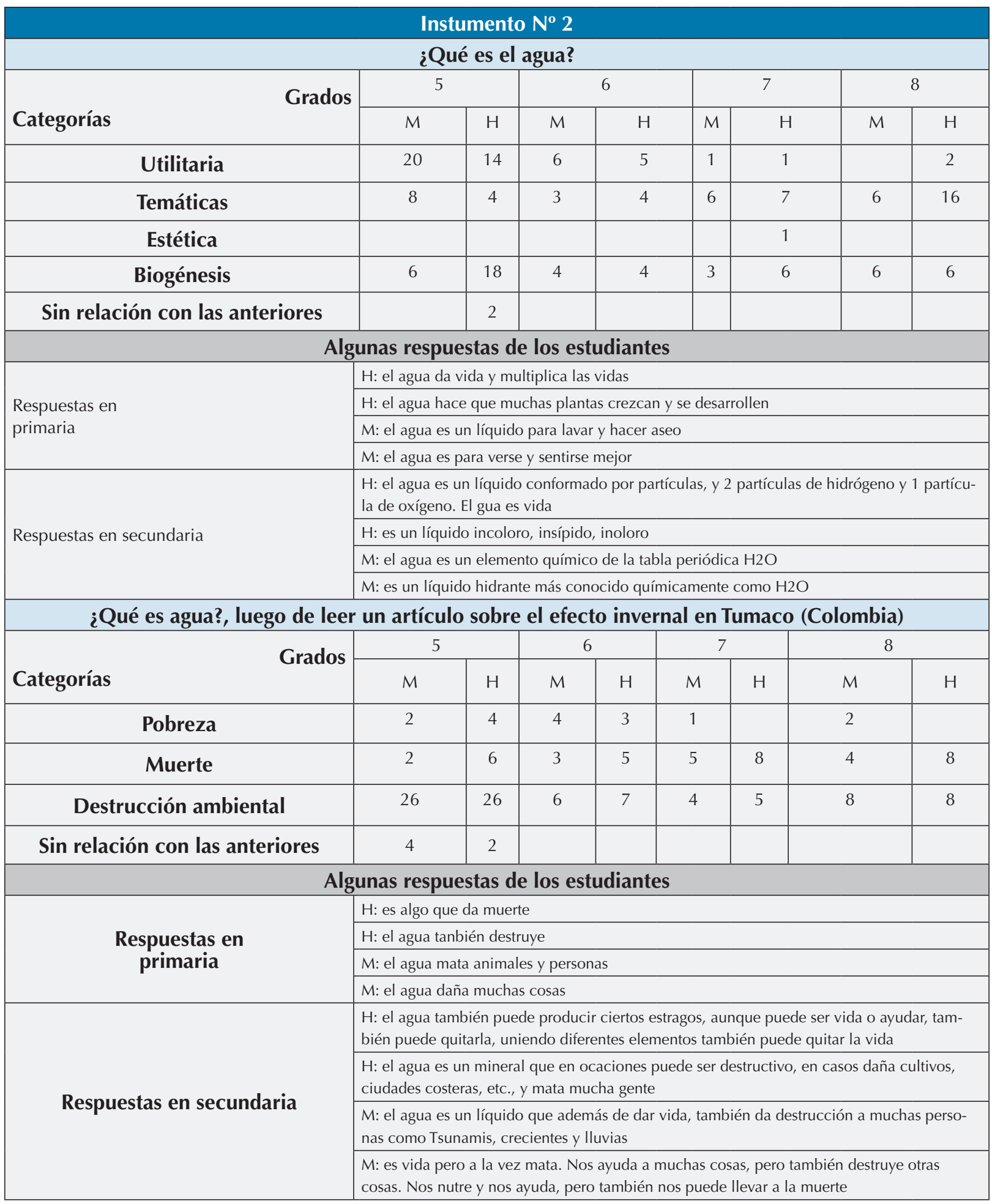

Tabla 2. Categorías y respuestas de los estudiantes 


\section{Instrumento $\mathrm{N}^{\circ} 3$}

El instrumento $\mathrm{n}^{\circ} 3$ se dessarrolló en tres momentos, el primero indaga acerca de 2 Qué es el $A H_{1} \mathrm{~N}_{1}$ ? , para luego organizar las respuestas de los y las estudiantes en las categorías muerte y salud, se evidencian en la Tabla 3.

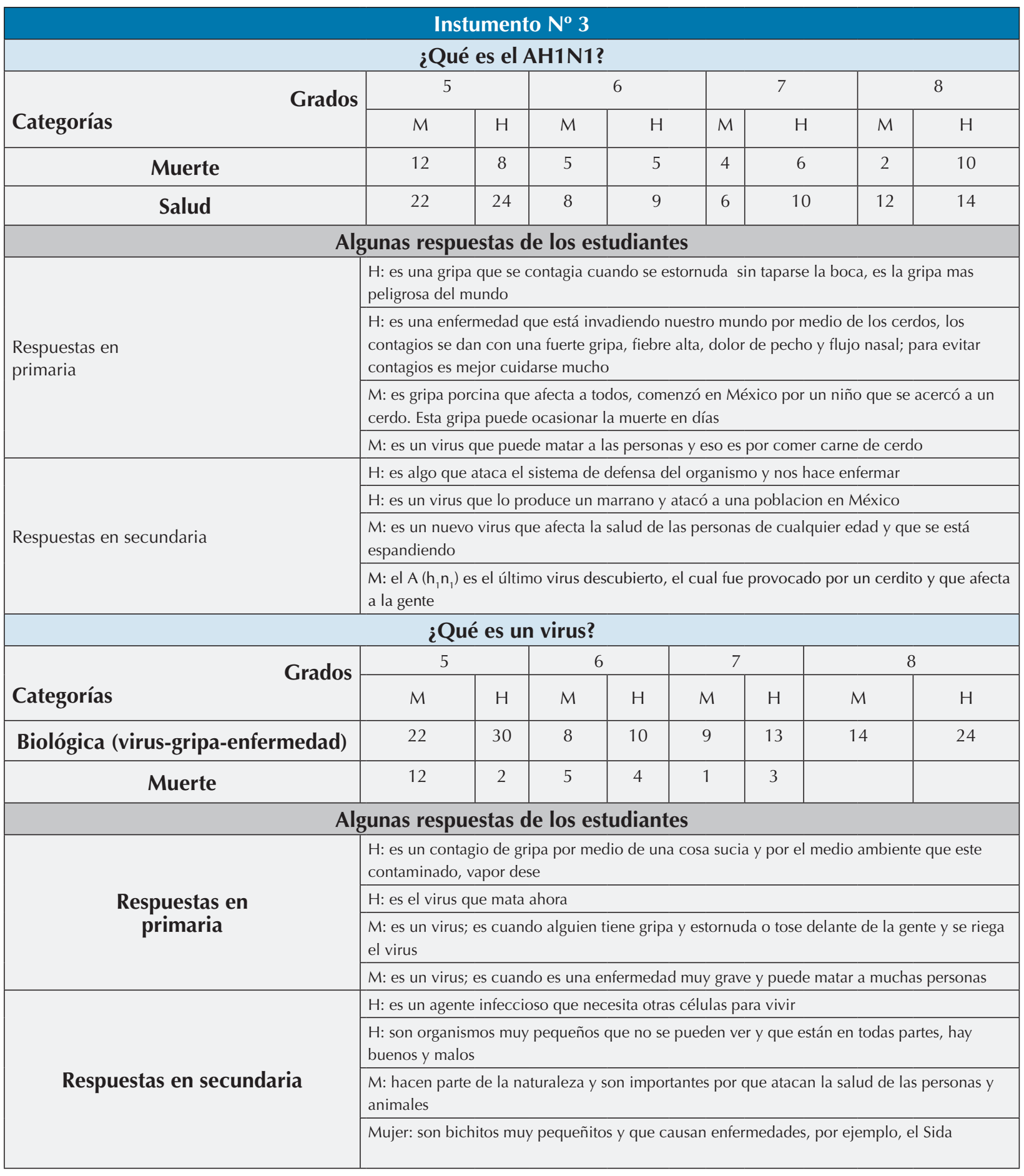




\begin{tabular}{|c|c|c|c|c|c|c|c|c|}
\hline \multicolumn{9}{|c|}{ Pregunta $i Q u e ́$ tiene que ver el agua con el AH1N1? } \\
\hline \multirow[b]{2}{*}{ Categorías } & \multicolumn{2}{|c|}{5} & \multicolumn{2}{|c|}{6} & \multicolumn{2}{|c|}{7} & \multicolumn{2}{|c|}{8} \\
\hline & M & $\mathrm{H}$ & M & $\mathrm{H}$ & M & $\mathrm{H}$ & M & $\mathrm{H}$ \\
\hline Protección & 8 & 14 & 5 & 7 & & & 2 & \\
\hline Contagio & 22 & 16 & 8 & 7 & 10 & 15 & 10 & 24 \\
\hline No responde & 4 & 2 & & & & 1 & 2 & \\
\hline \multicolumn{9}{|c|}{ Algunas respuestas de los estudiantes } \\
\hline \multirow{4}{*}{$\begin{array}{c}\text { Respuestas en } \\
\text { primaria }\end{array}$} & \multicolumn{8}{|c|}{$\mathrm{H}$ : que si una persona toma la misma agua de una persona con AH1N1 se infecta } \\
\hline & \multicolumn{8}{|c|}{$\mathrm{H}$ : para no producir el virus AH1N1 tenemos que lavar las manos muy bien } \\
\hline & \multicolumn{8}{|c|}{ M: que puede ayudar a calmar el virus Ah1N1 } \\
\hline & \multicolumn{8}{|c|}{ M: que si el agua está contaminada puede tener la gripa AH1N1 } \\
\hline \multirow{4}{*}{ Respuestas en secundaria } & \multicolumn{8}{|c|}{$\begin{array}{l}\text { H: porque cuando se consume agua cruda o cuando no nos lavamos las manos el virus A } \\
\mathrm{H}_{1} \mathrm{~N}_{1} \text { se nos puede prender }\end{array}$} \\
\hline & \multicolumn{8}{|c|}{$\begin{array}{l}\mathrm{H} \text { : el agua y el } \mathrm{A} \mathrm{H}_{1} \mathrm{~N}_{1} \text { se relacionan mucho porque por medio del agua hay virus, bichos y } \\
\text { otros seres que no vemos y que producen enfermedades que se pasan de persona en persona }\end{array}$} \\
\hline & \multicolumn{8}{|c|}{ M: el agua es la que nos proteje del virus del porcino cuando nos lavamos las manos } \\
\hline & \multicolumn{8}{|c|}{$\begin{array}{l}\text { M: Psss porque por medio del agua los virus se transmiten, por ejemplo, en el agua cruda } \\
\text { puede estar el virus }\end{array}$} \\
\hline
\end{tabular}

Tabla 3. Categorías y respuestas de los estudiantes

\section{Hallazgos y aportes}

El resultado de la presente investigación plantea la necesidad de revisar la relación entre cultura y curriculo en la escuela que se desarrolla en medio de un mundo globalizado; a continuacion se exponen algunos de los puntos más importantes:

\section{Análisis de la cultura}

Los mamíferos somos animales amorosos y seducibles, al convivir amorosos por lo menos en la infancia, y los seres humanos lo seguimos siendo toda la vida.

\section{Humberto Maturana}

En nuestros días se realiza un proceso de aculturización de los pueblos que busca cumplir con un proyecto de globalización en el que los procesos de identidad y diferencia de los grupos humanos, organizados alrededor de una postura de vida, ya no tiene cabida, pues se pretende que todo ser humano sea "democrático participativo", para lo que resulta necesario alcanzar el bienestar y el éxito, y la única manera de lograrlo es abriéndose un espacio en el circuito económico que impera.
A partir de lo anterior, situaremos el concepto de cultura desde la propuesta de Páramo (2000), que incluye dos distinciones: por un lado, "la cultura en lenguaje corriente, que hace referencia a un tipo de conocimiento sobre expresiones de una minoría, generalmente sofisticada, que se convierte en un grupo de referencia", por ejemplo, los literatos, cierta clase de música, ciertas maneras de actuar en la mesa, en el habla, etc.; mientras que, por otro lado, se encuentra la cultura en términos de los antropólogos, que consiste en: "toda producción humana, que es específica de una comunidad humana [...] es decir, la fenomenología cultural de lo que hace el hombre frente a la naturaleza y que configura entidades humanas específicas".

Lo expresado hasta este momento nos sitúa en dos marcos de referencia: por un lado, el cuestionamiento por la identidad cultural como propuesta filosófica, de relación con otros y con el planeta, y por otro lado, la función de la escuela en su papel de mediador con los desarrollos culturales de un pueblo en particular. Es en este marco en el que situamos al niño y a la niña como 
"sujetos de una simbología cultural" en la familia, y luego, a la escuela como espacio socializador cultural, teniendo en cuenta que los niños de cinco años, que ingresan al espacio escolar, son, como dice Gardner (1999): "criaturas plenamente simbólicas: personas que poseen una maestría del esbozo de la mayor parte de los sistemas simbólicos de su cultura. El niño puede leer y escribir en estos sistemas".

Esto implica, como plantea Piaget (1960), que el surgimiento del lenguaje se inserta en el marco global de la función simbólica, en el universo de significantes diferenciados (acciones pautas imitativas, palabras, dibujos). En muchos casos, las familias y la escuela no se interesan por implementar estrategias que busquen promover la identidad y el sentido de nuestra cultura, por el contrario, son espacios que refuerzan la aculturización de nuestros niños, principalmente cuando:

- Los adultos educadores, padres de familia, profesores y todo aquel que tenga responsabilidad social educativa, hacemos parte del circuito comercial y de consumo, sin cuestionamiento alguno.

- Los modelos educativos en la familia están basados en la obediencia y en la exigencia del consumo, en tanto la escuela se sirve de modelos pedagógicos y didácticos que continúan limitados al transmisionismo.

En consecuencia, se hace necesario propender por una escuela que permita la interacción entre sujetos y, más específicamente, una relación pedagógica en la que, desde una práctica de sentido para todos los participantes, debe emerger la consciencia ambiental, donde la intencionalidad de cada uno se (re) configure en tanto la intencionalidad del otro y de los otros, y se traduzca en acción o acciones significativas para sus participantes, de tal forma que, tal como afirma Canclini (2005): "Cultura y sociedad [mantengan] una relación generadora mutua", y en la que se considere que:

Si la cultura contiene en sí un saber colectivo acumulado como memoria social, si lleva en sí principios, modelos, esquemas de conocimiento, si genera una visión del mundo, si el lenguaje y el mito son parte constitutiva de la cultura, entonces la cultura no comporta únicamente una dimensión cognitiva: es una máquina cognitiva cuya práxis es cognitiva (Canclini, 2005).
La "Maquina cognitiva" mencionada, está relacionada con la que estaba constituída, para Morin, por los seres humanos que integraban esa comunidad en particular, y eran estos los que establecían los puentes modificadores de lo nuevo y lo socialmente transformador.

\section{Análisis desde el currículo}

Según Magendzo (2008), el proceso de globalización, que por supuesto no es nuevo y que tiene una historia instalada en la modernidad, ha tenido en estos últimos años un ritmo acelerado, una profundidad y amplitud significativas, y se manifiesta como una ruptura con las interacciones transnacionales y transfronterizas que han tenido lugar en el pasado. En la actualidad, la globalización constituye un fenómeno multifacético de dimensiones económicas, políticas, religiosas, jurídicas y culturales, relacionadas entre sí de modo complejo.

La cultura global es materia de análisis y de discusiones muy relevantes para el diseño del currículo, ya que incorpora, por ejemplo, preguntas como: ¿está realmente emergiendo una cultura mundialmente unificada, y si esto es así, cuáles son los efectos que tiene sobre la autonomía de las culturas existentes?; ¿serán éstas suplementadas por una cultura global-unificada o darán lugar a que se mantengan aquellos rasgos más sobresalientes y significativos de las culturas que definen a las identidades locales y nacionales?; ¿ hasta qué punto la globalización acarrea homogenización cultural?

Esto, sumado al trabajo investigativo, permite relacionar algunas respuestas de los estudiantes a una categoría que Ilamaremos currículo, que en nuestro caso hace parte de las temáticas escolares, en la que los estudiantes entretejen información que sólo será conocimiento cuando se conciba una reflexión. El currículo se estructura en beneficio de los individuos y la sociedad, $y$, debido a esta gran responsabilidad, está permeado por distintas visiones, por lo que se enfoca en varios problemas: ¿Qué debe la persona lograr ser?, ¿qué puede lograr ser?, ¿qué debemos enfatizar?

No puede olvidarse que toda conducta del hombre implica una interacción con el ambiente y que la educación es el instrumento por el cual se mantiene la continuidad social de la vida. El currículo debe otorgar más importancia a los procesos útiles para la búsqueda del conocimiento que al conocimiento mismo (Ortiz, 2000). Hay quienes interpretan el campo curricular 
desde las diversas perspectivas de la vida cotidiana y descubren una insospechada riqueza en la vida escolar que reclama ser conocida. Sus diversos instrumentos de aproximación les permiten dar cuenta de una serie de acontecimientos sobre los cuales no se ha reflexionado.

Esta situación los lleva a buscar modelos de conceptualización de esta realidad, que en ocasiones resultan "abigarrados", pero que, sin embargo, establecen un rigor conceptual en un lugar en donde lo que impera es el acontecimiento educativo en sí, a pesar de que resulte necesario reconocer que no siempre logran esta tarea y que tampoco ofrezcan un análisis que permita una mejor comprensión del acontecimiento educativo (Díaz, 2003).

En este contexto aparece una relación importante entre los medios de comunicación y el currículo; quizás la hacemos evidente sólo cuando creemos que una información es significativa y la obviamos cuando se transforman nuestras percepciones e ideas, ya que no proporciona una información acerca del mundo, sino maneras de verlo, entenderlo y configurarlo. Este hecho se hace evidente cuando se tienen en cuenta tesis como la de Tena (2002), en la que se insiste en que uno de los efectos de los medios es que la exposición progresiva a sus mensajes, nos lleva a modificar la concepción de la realidad por otra que es presentada por los medios; en otros términos nuestra exposición progresiva a sus mensajes y efectos, cultiva nuestra forma de entender y comprender el mundo.

Finalmente, resulta necesario resalta que en muchas ocasiones el currículo es desplazado por los medios de comunicación, que han creado nuevas formas de información, distorsionando el conocimiento y originando brechas entre lo real y lo inexistente. Esto genera la no comprensión, en toda su dimensión, de las buenas prácticas de enseñanza para la escuela. Los medios de comunicación venden su propio currículo, que finalmente se traduce en reflexiones no concordantes con la realidad y que, en nuestro caso, no permite el desarrollo de redes o círculos que generen consciencia ambiental.

\section{Consideraciones e implicaciones pedagógicas}

Lograr la participación de los estudiantes, a partir del análisis de temáticas relacionadas con nuestro entorno biológico, es sin duda uno de los mayores retos que debe sortear el ser humano. Pero, ¿qué podemos hacer desde nuestra labor docente?, sólo cuando sobrevive el concepto de lo que existe, y éste tiene eco en los organismos académicos y sociales, respondiendo a las necesidades, motivaciones e intereses de eso que Ilamamos cultura, es cuando verdaderamente se hace una integración. Las acciones de una consciencia ambiental tendrán reconocimiento curricular mediante la inserción de maniobras concretas y perdurables que se otorguen en cada nivel escolar.

\section{Conclusiones}

Los interrogantes planteados en el aula de clase se visualizan como interacciones que permiten generar o predecir emergencias para ser asumidas en forma de totalidad, lo que posibilita una mirada planetaria y de reflexión hacia el ser y el bienestar humano, que, en términos de Morin (2003), representaría una "simbiosis entre el mundo animal y el mundo vegetal: unos tienen necesidad de los otros, unos se regulan con respecto a los otros. Existe una economía del ecosistema".

Por otra parte, el trabajo con bucles permite a los estudiantes, profesores y padres de familia, "engatillar" preguntas que se desprendan de un gran árbol de problemas de su entorno, o interrogantes puntuales sobre temáticas teóricas tratadas en la escuela. Desde las aulas, y aunque parezca lejano, es importante fomentar el respeto por lo ambiental a través de un manejo sustentable de los recursos naturales, esto es, palpable a medida que reflexionemos como cuidamos sobre lo que producimos, lo que tenemos y lo que estamos haciendo, para disminuir los efectos negativos en el medio ambiente, en el bienestar de los ecosistemas y del propio ser humano. 
Allendes, P. (2005). La complejidad del conocimiento y el problema de la educación en el siglo XXI. Revista digital de Educación y Nuevas tecnologías, 35. Obtenido el 22 de Marzo de 2007, desde, http://contexto-educativo.com.ar/2005/2/nota-01.htm

Arroyo, M., y Mandolini, G. (2006). Trabajando en la construcción de un docente investigador. Revista Nodos y Nudos, 3(21), 17-31.

Caamaño, A. (1995). La educación CTS: una necesidad en el diseño del nuevo currículum de Ciencias. Revista Alambique, 3, 4-6.

Canclini, N. (2005). Todos tienen cultura: ¿quiénes pueden desarrollarla? Trabajo presentado en el Seminario sobre Cultura y Desarrollo, Banco Interamericano de Desarrollo, Washington, 24 de febrero de 2005. Obtenido el 22 de Marzo de 2007, desde, http://www.aulaintercultural.org/lMG/pdf/0202405canclini.pdf

Capra, F. (2003). Las conexiones ocultas. Barcelona: Anagrama.

Cardona, M. (2002). Introducción a los Métodos de Investigación en Educación. España: Editorial EOS.

Castro, D., et al. (2006). La escuela imaginada: opciones de autoformación, encuentros con la RED de Ciencias. Bogotá: Secretaría de Educación Distrital-Cooperativa Editorial Magisterio.

Castro, D., et al. (2006). Territorio y escuela. Un encuentro con el pensamiento ambiental. Bogotá: P.F.P.D. Convenio interadministrativo Universidad Pedagógica Nacional- Secretaría de Educación del Distrito Capital.

Castro, D., et al. (2007, Julio-Diciembre). La escuela como escenario de construcción de redes de vida planetaria. Revista Nodos y Nudos, 3(23), 95-102.

Díaz, A. (2003). Curriculum. Tensiones conceptuales y prácticas, 5(3).

Gadotti, M. (2002). Pedagogía de la tierra. México: Siglo veintiuno editores.

Gardner, H. (1999). Mentes extraordinarias. Barcelona: Kairos.

Giddens, A. (2001). Globalización, desigualdad y estado de la inversión social. Informe mundial sobre la cultura 2000-2001. Diversidad cultural, conflicto y pluralismo. París: Organización de las Naciones Unidas para la Educación, la Ciencia y la Cultura (UNESCO) y Mundi-Prensa.

Hernández, S., Fernández, C., y Baptista, L. (2006). Metodología de la investigación. México: McGraw Hill.

Lovelock, J. (1993). Las edades de GAIA: una biografía de nuestro planeta vivo. Barcelona: Metatemas.

Magendzo, A. (2008). Isomorfismo curricular: sociedad global y sociedad del conocimiento en el contexto de una sociedad democrática. Obtenido el 22 de Febrero de 2010, desde, http:// mt.educarchile.cl/mt/amagendzo/archives/ curriculumeducacion/
Morín, E. (1998). El método IV. Las ideas. Madrid: Cátedra, 19.

Morín, E., y Kern, A. (1999). Tierra patria. Argentina: Ediciones Nueva visión.

Morín, E. (2003). El método Il: la vida de la vida. Madrid: Cátedra.

Muñoz, A. (1996). Algunas contribuciones de la mujer a las ciencias experimentales. Revista Enseñanza de las Ciencias. 14(2), 233-237.

Odum, E., y Sarmiento, F. (2001). Ecología: el puente entre ciencia y sociedad. México: Magra-Hill Interamericana.

Olavarria, J. (2008, Noviembre-Diciembre). Globalización, género y masculinidades. Revista Nueva Sociedad, 218, 73-74.

Ortíz, J. (2000). Fundamentos del curriculo. Obtenido el 22 de Febrero de 2010, desde, http://www.pucpr.edu/.../LosFundamentosdelCurrículo.pdf

Páramo, G. (2000). Otras culturas, otros mundos. Planteamientos No 4. El ambiente educativo y conocimiento y cultura. Bogotá: Escuela Pedagógica Experimental, 200.

Quiles, O. (2004). Fundamentos y retos de educación social-informal desde el análisis crítico de los medios de comunicación. Trabajo presentado en el Primer congreso virtual latinoamericano de educación a distancia.

Sarramona, J. (2003). Dimensión Educativa de los medios de comunicación. Madrid: Narcea S.A. Ediciones.

Sahuquillo, E., Jiménez, A., Domingo, F., y Álvarez, M. (1993). Un currículo de ciencias equilibrado desde la perspectiva de género. Revista Enseñanza de las Ciencias, 11(1), 51-58.

Segura, D. (1999, Enero-Julio). El conocimiento escolar, el desconocimiento escolar. Revista Nodos y Nudos. Bogotá: Universidad Pedagógica Nacional.

Segura, D. (2006). La educación ambiental en la escuela. Bogotá: EPE

Solbes, J., y Vilches, A. (1989). Interacciones Ciencia-Tecnología-Sociedad: un instrumento de cambio actitudinal. Revista Enseñanza de las Ciencias, 7(1), 14-20.

Susi, E. (1994). Ciencia y género: autoridad y medida en la enseñanza. Revista Enseñanza de las Ciencias, 12(2), 200-205.

Tena, R. (2002). Los medios de comunicación en el ámbito curricular. Sevilla: Universidad de Sevilla. Obtenido desde, http:// tecnologiaedu.us.es/revistaslibros/public7.htm. 


\section{Diálogo del Conocimiento}

Como editor de publicaciones pedagógicas no me dejo de sorprender con los proyectos de investigación que realizan los maestros, el interés y la metodología, sobre todo esta. En este artículo se deja ver claramente el trabajo de sistematización de una investigación, que toca el trasfondo de lo actual, no solo por lo que representa la conciencia ambiental, o los medios de comunicación, sino por el carácter de poder ir más allá y pensar en el trabajo con los estudiantes, retomar el currículo y replantearlo, porque no podemos pensar en los interés que presentan nuestros estudiantes, qué es lo que les gusta, en realidad desde sus capacidades y gustos pueden cambiar su contexto. Siempre estamos aferrados a los que nos dice un manual y estas preguntas que se plantean en el texto nos dan la posibilidad de repensar nuestro trabajo: 1) Desde los espacios de los medios de comunicación, de la comunidad y los contextos propios de la escuela ¿Cómo se identifican los lenguajes que circulan en los sujetos que asisten a la escuela? 2) ¿Qué papel cumple la escuela en la relación medios de comunicación y contextos sociales?

Con este par de preguntas se lleva a cabo un trabajo de campo que logra ir despejando un sin número de dudas. Los instrumentos utilizados con diferentes preguntas nos dejan ver con claridad un arcoíris de respuestas, que de alguna manera son influenciadas por los medios y la globalización. El cuestionamiento sobre la cultura y para ello tomo un apartado del artículo "Esto implica, como plantea Piaget (1960), que el surgimiento del lenguaje se inserta en el marco global de la función simbólica, en el universo de significantes diferenciados (acciones pautas imitativas, palabras, dibujos). En muchos casos, las familias y la escuela no se interesan por implementar estrategias que busquen promover la identidad y el sentido de nuestra cultura, por el contrario, son espacios que refuerzan la aculturización de nuestros niños...”

El texto como ser que se recrea continuamente nos va mostrar los diferentes caminos que debería tomar la escuela para poder sobrepasar el peso de los medios y la globalización, pero más que la escuela son los maestros, padres y estudiantes. Como cierre de la sistematización se piensaen el medio ambiete, en la posibilida de ser constructores y no destructores. Como una persona más de las que habitan esta isla me pregunto si hago lo suficiento, pero luego replanteo y se que lo suficiente no existe y por tal motivo cada día debo hacer lo mejor.

Daniel Torres $P$. 